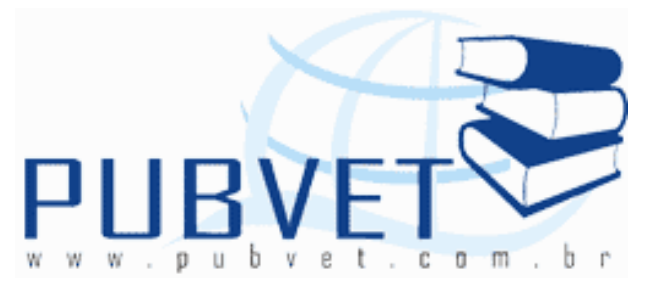

PUBVET, Publicações em Medicina Veterinária e Zootecnia.

\title{
Utilização de bioestimulantes na cultura da cana-de-açúcar (Saccharum officinarum L.)
}

\section{Newton de Lucena Costa ${ }^{1}$, Edelclaiton Daros ${ }^{2}$ e Anibal de Moraes ${ }^{3}$}

${ }^{1}$ Eng. Agr., M.Sc., Embrapa Roraima, Doutorando em Agronomia/Produção Vegetal, UFPR, Curitiba, Paraná. E-mail: newton@cpafrr.embrapa.br

${ }^{2}$ Eng. Agr., D.Sc., Professor Adjunto, UFPR, Curitiba, Paraná. E-mail: ededaros@ufpr.br

${ }^{3}$ Eng. Agr., D.Sc., Professor Associado II, UFPR, Curitiba, Paraná. E-mail: anibalm@ufpr.br

\section{Resumo}

O uso de bioestimulantes na cultura da cana-de-açúcar (Saccharum officinarum L.) é uma prática de manejo que potencialmente pode incrementar sua produtividade e o seu rendimento industrial, favorecendo o bom desempenho dos processos vitais da planta, permitindo obter melhores e maiores colheitas, mesmo sob condições ambientais adversas. Para o efeito desejado com o uso de bioestimulantes específicos é importante conhecer o processo regulado pelo hormônio ou grupo de hormônios, a dose necessária para manipular o processo, bem como o órgão da planta onde ocorrerão as reações biológicas. Por sua composição de múltiplos hormônios em baixas concentrações, bem como pelas pequenas doses recomendadas, a aplicação isolada de um bioestimulante dificilmente poderá regular ou manipular 
completamente um processo fisiológico. O bioestimulante será um complemento no auxílio da manutenção fisiológica, o que pode ser muito importante em condições ambientais (seca, geada) ou bióticas limitantes (pragas e doenças).

Palavras-chave: balanço hormonal, bioativador, biorregulador vegetal, metabolismo

\title{
Utilization of biostimulants in the sugarcane (Saccharum officinarum L.) culture
}

\begin{abstract}
The use of biostimulants in the sugarcane (Saccharum officinarum L.) culture is a management practice that potentially can increase its productivity and the industrial performance, favoring the higher performance of the vital physiological phenomena involved in the biomass and sugar accumulation by the plant, permitting obtain better and higher harvests, even under adverse environmental conditions. For the effect desired with the use of specific biostimulants is important know the physiological process regulated by the hormone or group of hormones, the adequate dose for biological process manipulate, as well the organ of the plant where will occur the reactions. By its composition of multiple hormones in lower concentrations, as well by lower doses recommended, the application of a biostimulant alone hardly will be able to regular or manipulate a physiological process. Thus, the biostimulant will be a complement in the maintenance of the physiological process, what can be very important role to maximizes growth plants under environmental (dry, frost) and biotics (pests and diseases) adverse conditions.
\end{abstract}

Keywords: bioativate, bioregulator vegetable, hormonal balance, metabolism 


\section{Introdução}

Uma planta para crescer necessita de luz, $\mathrm{CO}_{2}, \mathrm{H}_{2} \mathrm{O}$ e minerais. A planta faz mais do que simplesmente aumentar sua massa e volume. Ela se diferencia, desenvolve-se e adquire forma criando uma variedade de células, tecidos e órgãos. O crescimento do tecido vegetal ocorre pela divisão e alongamento celular nas regiões meristemáticas da planta. Estes dois processos irão promover o crescimento da planta em altura pelo alongamento do caule, diferenciação dos órgãos, bem como o aumento do comprimento das folhas (TAIZ; ZEIGER, 2009). Os principais fatores que interferem no crescimento e desenvolvimento das plantas são de natureza química. Os hormônios, responsáveis pelos sinais químicos, carregam informações e modificam o estado fisiológico das células, dos tecidos e, em alguns casos de sistemas mais complexos. Nesse contexto, uma mesma substância pode produzir respostas diferentes em diferentes fases do desenvolvimento da planta. A partir do conhecimento das ações dos principais grupos de hormônios vegetais (auxina, citocinina, giberelina, citocinina, etileno e brassinoesteróides) tornou-se claro que sinais químicos adicionais são utilizados pelas plantas (RAVEN et al., 2001).

O crescimento e o desenvolvimento de plantas são regulados tanto por fatores endógenos como por fatores externos. Os fatores endógenos são ativos não somente em nível celular e molecular, afetando os processos metabólicos via transcrição e tradução, mas têm também a função de coordenação do organismo como um todo, realizada por meio dos hormônios vegetais. A importância ecológica dos hormônios vegetais está em sua função de substância transdutora; seguindo a percepção dos estímulos ambientais, todas as partes da planta são informadas sobre a situação de outras partes por meio da síntese ou de mudanças de concentração de um ou mais fitormônios. Como hormônio vegetal, que está envolvido em determinada ação, depende do estádio de desenvolvimento e da atividade da planta, da natureza e do estímulo externo, da parte da planta que está recebendo o estímulo e do 
COSTA, N.L., DAROS, E. e MORAES, A. Utilização de bioestimulantes na cultura da cana-deaçúcar (Saccharum officinarum L.). PUBVET, Londrina, V. 5, N. 22, Ed. 169, Art. 1137, 2011.

tempo deste impacto. A reação resultante, seja ela sinergista ou antagonista, pode variar muito, dependendo do órgão em questão e da predisposição da planta. Junto com fatores externos, os fitormônios iniciam o processo do crescimento e da diferenciação, bem como sincronizam o desenvolvimento da planta com as mudanças sazonais do ambiente. Outras funções dos hormônios vegetais são a regulação da intensidade e da orientação do crescimento, da atividade metabólica, do transporte, do estoque e da mobilização de materiais nutritivos (LARCHER, 2006). Reguladores endógenos podem estar envolvidos em vários processos durante o desenvolvimento das sementes, como crescimento e desenvolvimento, tecidos extra-seminais, na acumulação e armazenamento de reservas e diversos efeitos fisiológicos em tecidos e órgãos (BEWLEY; BLACK, 1994).

Os hormônios vegetais são compostos orgânicos, não nutrientes, produzidos na planta, os quais em baixas concentrações $\left(10^{-4} \mathrm{M}\right)$, promovem ou inibem processos fisiológicos e morfológicos do vegetal (CASTRO; VIEIRA, 2001b; MONTANS, 2007). Conforme Taiz e Zeiger (2009), oito grupos de substâncias são consideradas hormônios vegetais: auxinas, guberelinas, citocininas, etileno, ácido abscísico, brassinoesteróides, jasmonatos e salicilicatos, os quais atendem às premissas relativas ao conceito atual de hormônios vegetais. As $\ulcorner$ biomoléculas $\ulcorner$ são $\ulcorner$ responsáveis $\ulcorner$ por uma infinidade de importantes eventos nas plantas, desde a divisão celular, no interior de um tecido, até os fenômenos mais externos e tangíveis, como o alongamento do caule, floração, frutificação, entre outros (VALOIS, 2000). Elas controlam o metabolismo, o crescimento e a morfogênese de plantas superiores por meio de sinais transmitidos de uma parte a outra da planta, funcionando como "mensageiros químicos", influenciando em muitas partes do desenvolvimento das plantas (HARTMANN et al., 1988; TAIZ; ZEIGER, 2009). Raramente, os hormônios vegetais agem isoladamente, mesmo quando uma resposta no vegetal é atribuída à aplicação de um único regulador, pois o tecido vegetal que recebeu a aplicação possui hormônios endógenos que influenciam nas respostas obtidas (CATO, 2006) 
COSTA, N.L., DAROS, E. e MORAES, A. Utilização de bioestimulantes na cultura da cana-deaçúcar (Saccharum officinarum L.). PUBVET, Londrina, V. 5, N. 22, Ed. 169, Art. 1137, 2011.

Processos como germinação, crescimento vegetativo, florescimento, frutificação e maturação são afetados por diversos fatores, sendo que os hormônios vegetais desempenham um papel importante no controle do desenvolvimento dos componentes que interferem na produtividade. Conhecer os locais de produção, biossíntese, vias de transporte, estrutura química, mecanismo de ação e efeitos fisiológicos destas substâncias é importante para estudos que visam alterar as respostas das plantas, através de sua manipulação e/ou a aplicação de seus similares (CATO, 2006).

A seqüência de eventos iniciada por hormônios pode geralmente ser resumida em três fases sequenciais: 1 . o primeiro sinal de percepção; 2. o sinal de transdução do percurso e, 3. a resposta final. O sinal de percepção envolve a reação do hormônio com um receptor. Os fitormônios podem moverse por difusão entre as células através dos plasmodesmas ou pelo espaço apoplástico. Deste modo, as células destinadas a responder ao hormônio, conhecidas como células-alvo, devem ser capazes de detectar a sua presença no espaço celular ou em fluídos imediatamente circundantes da célula. O sinal de transdução ocorre quando é ativado o complexo hormônio-receptor, em andamento conjunto a uma cascata de eventos bioquímicos que acaba por conduzir à característica final de resposta (WENT; THIMANN, 1999).

\section{Hormônios Vegetais}

\subsection{Auxinas}

A auxina foi o primeiro fitohormônio descoberto sendo um dos agentes químicos sinalizadores que regulam o desenvolvimento vegetal (ARTECA, 1995). Em plantas superiores, a principal auxina é o ácido indolil-3-acético (AIA), embora existam várias auxinas que ocorrem naturalmente, tais como o ácido fenilacético (PAA), o ácido indol-3-butírico (IBA) e o ácido 4-cloroindolil3-acético (4-Cl-IAA) e como sintéticas o ácido 2,4-diclorofenoxiacético (2,4-D) e o ácido 2-metóxi-3,6-diclobenzóico (dicamba)(RODRIGUES; LEITE, 2004; 
COSTA, N.L., DAROS, E. e MORAES, A. Utilização de bioestimulantes na cultura da cana-deaçúcar (Saccharum officinarum L.). PUBVET, Londrina, V. 5, N. 22, Ed. 169, Art. 1137, 2011.

TAIZ; ZEIGER, 2009). As auxinas sintéticas são bastante eficientes, pois não são metabolizadas pelas plantas tão rapidamente quanto o AIA; um grande número de auxinas sintéticas já foi produzido, como as substâncias indólicas, os derivados dos ácidos fenoxiacéticos e do ácido benzóico e os tricarbamatos (TAIZ; ZEIGER, 2009), tais como o ácido naftalenoacético (ANA), o ácido 2,4-diclofenóxiacético (2,4-D) e o ácido indolbutírico (IBA) (CASTRO; VIEIRA, 2001a).

Auxina é um grupo hormonal caracterizado pela sua capacidade de induzir o alongamento celular localizado nas regiões subapicais. São sintetizadas em tecidos meristemáticos de órgãos aéreos, tais como gemas em brotação, folhas jovens, extremidades da raiz e flores ou inflorescências em crescimento. As auxinas promovem a expansão celular, pois estão envolvidas na incorporação de materiais na parede celular, através do aumento da sua plasticidade. Geralmente, as auxinas são ácidos contendo um núcleo indol insaturado ou seus derivados, atuando no mecanismo de controle do crescimento do caule, folhas, raízes, iniciação da atividade cambial e dominância apical.

A auxina participa principalmente na promoção do crescimento de caules, além da regulação da dominância apical, da iniciação das raízes laterais, da abscisão foliar, da diferenciação vascular, da formação de gemas florais e do desenvolvimento do fruto. A auxina é sintetizada principalmente na gema apical e translocada de modo polar para a raiz e o seu transporte ocorre preferencialmente nas células do parênquima associadas ao tecido vascular (TAIZ; ZEIGER, 2009). A concentração de auxina na planta não é uniforme, diminui ao longo do caule. Em ordem decrescente de concentração tem-se: ápice caulinar, gemas de crescimento, sementes em formação, folhas novas, folhas maduras, grãos de pólen e câmbio. Em geral, a auxina na planta diminui com a idade, época do ano e atividade metabólica, sendo que a presença de microrganismos também pode estar associada à síntese de auxina (DAVIES, 2004). As auxinas possuem ação característica no crescimento celular, agindo diretamente no aumento da plasticidade da parede celular, conferindo-Ihe 
COSTA, N.L., DAROS, E. e MORAES, A. Utilização de bioestimulantes na cultura da cana-deaçúcar (Saccharum officinarum L.). PUBVET, Londrina, V. 5, N. 22, Ed. 169, Art. 1137, 2011.

alongamento irreversível (VIEIRA; MONTEIRO, 2002), o qual requer a entrada de água e a síntese de material para reconstrução da parede celular. A auxina promove o crescimento por alongamento, sobretudo por aumentar a capacidade de extensão da parede celular.

\subsection{Giberelinas}

As giberelinas foram caracterizadas na década de 1950, as quais constituem um grande grupo de compostos relacionados, sendo conhecidos mais de 125, que, ao contrário das auxinas, são definidos mais por sua estrutura química que por sua atividade biológica. As giberelinas atuam ativamente na germinação das sementes por induzirem, via ação gênica, a síntese de enzimas da lise que promovem a quebra e a mobilização de substâncias de reserva no seu endosperma. Aparecem também no crescimento (alongamento do caule), no desenvolvimento reprodutivo, além de afetar a transição do estado juvenil para o maduro, bem como a indução da floração, a determinação do sexo e o estabelecimento do fruto (TAIZ; ZEIGER, 2009) e ainda no comprimento dos internódios, na área foliar e no acúmulo de matéria seca (STEFANINI et al., 2002).

As giberelinas são compostos terpênicos formados de unidades isoprênicas. Apenas certas giberelinas, em particular $\mathrm{GA}_{1}$ e $\mathrm{GA}_{4}$, são responsáveis pelos efeitos nas plantas; as demais são precursores ou metabólitos. Esses hormônios estimulam o alongamento e a divisão celulares. As mitoses aumentam de modo notável na região subapical do meristema de plantas em roseta sob dias longos (TAIZ; ZEIGER, 2009).

Os efeitos da giberelina no crescimento e no desenvolvimento são: estímulo do crescimento do caule em plantas anãs e rosetas; regulação da transição da fase juvenil para a adulta, iniciação floral e a determinação do sexo, promoção da frutificação e da germinação de sementes (TAIZ; ZEIGER, 2009). A ação das giberelinas (GAs) ou dos ácidos giberélicos no processo germinativo é bem conhecido, atuando no controle da hidrólise do tecido de 
COSTA, N.L., DAROS, E. e MORAES, A. Utilização de bioestimulantes na cultura da cana-deaçúcar (Saccharum officinarum L.). PUBVET, Londrina, V. 5, N. 22, Ed. 169, Art. 1137, 2011.

reserva para o fornecimento de energia ao embrião, promovendo o alongamento celular e o desenvolvimento da radícula através do endosperma ou tegumento (METIVIER, 1979).

Os principais usos das giberelinas aplicadas por aspersão ou imersão incluem o controle do cultivo de frutas, a maltagem da cevada e o aumento da produção de sacarose em cana-de-açúcar. Em algumas plantas cultivadas, a redução na altura é desejável, o que pode ser obtido pelo uso de inibidores da síntese de giberelinas (TAIZ; ZEIGER, 2009). As giberelinas afetam muitos aspectos do crescimento e desenvolvimento das plantas. Embora seja mais conhecida sua ação no alongamento, as GAs também afetam os processos reprodutivos de uma ampla variedade de plantas. As GAs podem induzir a formação de cones em coníferas e para plantas que necessitam de dias longos para floração, ou que requerem um tratamento frio, uma aplicação de GA pode substituir o sinal ambiental. As GAs retardam a senescência de folhas e frutos e promovem a germinação (CAMILI, 2007).

Os níveis mais altos de GAs foram encontrados em sementes imaturas e nos frutos em desenvolvimento. Entretanto, pelo fato de o nível normalmente decrescer a zero em sementes maduras, não há evidências de que as plântulas obtêm qualquer GA ativa das suas sementes. As GAs são sintetizadas nos tecidos apicais e podem ser transportadas para o resto da planta por meio do floema. Os intermediários da síntese de GAs podem também ser translocados no floema. As etapas iniciais da biossíntese de GA podem ocorrer em um tecido e o metabolismo torná-la ativa em outro (TAIZ; ZEIGER, 2009).

\subsection{Citocinina}

O nome citocinina é devido à ação desta substância sobre a citocinese (COLL et al., 2001). As citocininas foram descobertas durante pesquisas sobre os fatores que estimulavam as células vegetais a se dividirem. Com o interesse de pesquisadores na técnica de cultura de tecidos, as pesquisas se intensificaram na busca de um agente indutor de divisão celular, sendo 
COSTA, N.L., DAROS, E. e MORAES, A. Utilização de bioestimulantes na cultura da cana-deaçúcar (Saccharum officinarum L.). PUBVET, Londrina, V. 5, N. 22, Ed. 169, Art. 1137, 2011.

testadas muitas substâncias. Em 1954, a cinetina foi isolada em esperma de arenque. A partir do isolamento da cinetina, citocininas sintéticas foram produzidas em laboratório pela modificação na cadeia lateral na posição N-6 da base da adenina. Apenas em 1963, Lethan fez a extração e a critalização de uma citocinina natural de plantas, a partir do endosperma imaturo de sementes de milho, a qual foi chamada de zeatina, a qual é a citocinina natural mais ativa já conhecida (VALOIS, 2000; DAVIES, 2004). As citocininas de ocorrência natural são encontradas como moléculas livres, não ligadas a nenhuma macromolécula, bem como bases modificadas em certas moléculas de RNA transportador. A síntese das citocininas ocorre em raízes, em embriões em desenvolvimento e em tecidos de galhas de coroa. A zeatina é, geralmente, a citocinina mais abundante, contudo a diidrozeatina e a isopenteniladenina são comumente encontradas em plantas superiores (RODRIGUES; LEITE, 2004).

As citocininas são substâncias derivadas da base nitrogenada adenina e seus efeitos na planta estão relacionados à capacidade de divisão, alongamento e diferenciação celular, além de mobilização de nutrientes, formação e atividade dos meristemas apicais, quebra da dominância apical, retardamento da senescência de folhas e frutos, germinação de sementes, superação da dormência de sementes e gemas, indução do florescimento e da partenocarpia em frutos. De maneira geral, a citocinina promove a síntese de proteínas impedindo a senescência. Também impede a saída de proteases do vacúolo, inibindo a degradação de proteínas, inibe a formação de radicais livres mantendo a integridade da membrana plasmática, e a degradação da clorofila, mantendo a síntese de carboidratos (CASTRO; VIEIRA, 2001b; COLL et al., 2001; DAVIES, 2004). As citocininas estão envolvidas no desenvolvimento de organelas, na atividade enzimática, na abertura estomática, no desenvolvimento de frutos e na hidrólise de reservas de sementes (SALISBURY; ROSS, 1994; DAVIES, 2004). A citocinina é responsável pela citocinese durante o processo de divisão celular, além de participar do processo de alongamento e diferenciação celular, principalmente quando interage com as auxinas (TAIZ; ZEIGER, 2009). 
A concentração de citocinina pode variar em função do órgão considerado, do estado de desenvolvimento da planta, bem como das condições ambientais. De modo geral, as maiores concentrações são encontradas em regiões meristemáticas ou em órgãos em crescimento com altas taxas de divisão celular, como folhas jovens, sementes em desenvolvimento, frutos e raízes. No entanto, o meristema apical da raiz é o principal local de síntese de citocininas, as quais são translocadas, via xilema, para a parte aérea da planta $e$, quando se encontram nas folhas são relativamente imóveis (COLL et al., 2001; VIEIRA; CASTRO, 2004; TAIZ; ZEIGER, 2009).

\subsection{Etileno}

A primeira menção que o etileno era um produto natural de tecidos vegetais foi publicada por H.H. Cousins, em 1910, que relatou que "emanações" das laranjas armazenadas em uma câmara causavam o amadurecimento precoce das bananas quando em contato com esses gases. No entanto, visto que as laranjas sintetizam relativamente pouco etileno em comparação com outros frutos, como maçãs, por exemplo, é provável que as laranjas utilizadas por Cousins estivessem infectadas com o fungo Penicillium, produtor de grandes quantidades de etileno. Em 1934, R. Gane e colaboradores identificaram quimicamente o etileno como um produto natural do metabolismo vegetal, o qual, devido aos seus drásticos efeitos sobre a planta, foi classificado como um hormônio (CAMILI, 2007; TAIZ; ZEIGER, 2009).

O etileno pode ser produzido em quase todas as partes dos vegetais superiores. Em geral, as regiões meristemáticas e as regiões dos nós são as mais ativas na síntese de etileno. Contudo sua produção aumenta também durante a abscisão foliar e a senescência da flor, bem com o amadurecimento de frutos. Qualquer tipo de lesão pode induzir a biossíntese do etileno, assim como o estresse fisiológico provocado por inundação, resfriamento, moléstias, 
temperatura e estresse hídrico (TAIZ; ZEIGER, 2009). É um dos hormônios vegetais mais usados na agricultura, devido a seus efeitos sobre muitos processos fisiológicos. É difícil aplicá-lo nas plantas em condições de campo, pois se trata de um gás, sendo normalmente utilizado um composto chamado ethephon ou ácido 2-cloroetilfosfônico. A aplicação é feita com pulverizações da solução aquosa do produto, a qual é facilmente absorvida pela planta. O etileno é liberado após uma reação química que ocorre dentro da planta (VALOIS, 2000; CAMILI, 2007; TAIZ; ZEIGER, 2009).

Os principais usos comerciais do etileno são os seguintes: na cultura da seringueira, a aplicação no painel de extração de látex aumenta a produção; nos cafeeiros, aumenta o número de frutos; na cultura do algodão, o ethephon é utilizado para induzir ao desfolhamento $(70 \%$ do algodão produzido nos Estados Unidos são tratados por esse processo); na canade-açúcar provoca o encurtamento dos entrenós, obtendo uma maior concentração de sacarose; em plantas de tomate e de maçã, o amadurecimento dos frutos é acelerado e no abacaxi, o florescimento da lavoura é sincronizado (VALOIS, 2000).

\section{5. Ácido Abscísico (ABA)}

O ABA é um sesquiterpeno de 15 carbonos derivado da violaxantina, o qual é um produto da degradação dos caratenóides. Em condições de estresse hídrico verifica-se sua síntese a partir do ácido mevalônico em cloroplastos e outros plastídeos da folha. O ABA atua como inibidor de crescimento, além de estar relacionado com os processos fisiológicos de fechamento dos estômatos, dormência de gemas, germinação de sementes, abscisão de folhas e frutos e resposta da planta ao estresse hídrico. 


\subsection{Brassinoesteróides}

São derivados do 5-a-cholestano e encontrados em dicotiledôneas, monocotiledôneas, gimnospermas e algas. Seu local de síntese ainda não é conhecido, mas podem ser encontrados em várias partes vegetais, tais como grãos de pólen, folhas, frutos, caules e brotos, porém nunca em raízes. Atuam na promoção da biossíntese do etileno, alongamento das hastes, inibição do crescimento e no desenvolvimento de raízes.

\subsection{Jasmonatos}

Os jasmonatos são representados pelo ácido jasmônico, que é um metiléster de ocorrência em todo o reino vegetal, incluindo plantas superiores, samambaias, musgos e fungos. Alguns de seus efeitos são similares aos do ABA e do etileno, participando na senescência, biossíntese do etileno, fechamento estomático, promovendo a tuberização e inibindo a germinação de sementes.

\subsection{Salicilicatos}

Classe de compostos que possuem atividades similares ao ácido salicílico. Foram identificados em folhas e estruturas reprodutivas de plantas, com um alto nível em inflorescências de plantas termogênicas e/ou infestadas por patógenos necrófitos. Atuam no florescimento, produção de calor em plantas termogênicas, promoção de resistência a doenças, inibição da síntese de etileno e germinação de sementes.

\subsection{Interação Citocinina e Auxina}

Dentre os fatores que regulam o processo germinativo, a presença de hormônios e o equilíbrio entre eles, promotores e inibidores, exercem um 
COSTA, N.L., DAROS, E. e MORAES, A. Utilização de bioestimulantes na cultura da cana-deaçúcar (Saccharum officinarum L.). PUBVET, Londrina, V. 5, N. 22, Ed. 169, Art. 1137, 2011.

papel fundamental (CATO, 2006). Auxinas, citocininas e suas interações são consideradas, geralmente, como as mais importantes para a regulação do crescimento e desenvolvimento organizado em culturas de células, tecidos e órgãos de plantas (GASPAR et al., 1996). Segundo Davies (1987), as citocininas apresentam grande habilidade de indução da divisão celular em culturas de tecidos, juntamente com as auxinas. Para o estabelecimento de um efetivo controle no crescimento e na diferenciação das culturas in vitro, $\ulcorner$ é $\ulcorner$ preciso $\ulcorner$ um $\ulcorner$ balanço $\ulcorner$ ideal entre auxinas e citocininas (ANDRADE, 2006). Além da relação auxina/citocinina, o tipo e a concentração de auxina ou citocinina também afetam o crescimento e a produção de metabólitos em cultivos in vitro de plantas (RAMACHANDRA RAO; RAVISHANKAR, 2002).

As concentrações mais utilizadas destes hormônios, normalmente giram e torno de 0,5 a 5,0 mg/L (AYUB; GEBIELUCA, 2003). Por meio do uso da razão entre citocinina e auxina se pode obter calos, raízes ou ramos. A possibilidade de regeneração de plantas a partir de calos é uma ferramenta biotecnológica comumente utilizada para a seleção de plantas com resistência à seca, estresse salino e danos por herbicidas (SALISBURY; ROSS, 1994). Na presença de certas concentrações de citocininas e auxinas as células podem manter-se indiferenciadas (VALOIS, 2000). Em meios com razões intermediárias de auxina e citocinina ocorre proliferação celular desorganizada como calos (TAKAHASHI, 2002).

As auxinas e citocininas atuam sinergicamente para regular divisão celular e de forma antagônica para controlar a formação de gemas e raízes laterais, sugerindo múltiplos mecanismos de interação (CATO, 2006). Em segmentos de caule excisado de ervilha (Pisum sativum L.) foi observado um efeito sinérgico de citocinina e auxina na xilogênese (SOROKIN et al., 1962; SALISBURY; ROSS, 1994; TAIZ; ZEIGER, 2009), confirmando a Teoria do Balanço Hormonal, segundo a qual a formação de calos é favorecida pela combinação de pelo menos uma auxina e uma citocinina (CALDAS et al., 1990). Em cultura de tecidos de Tabebuia caraiba, a formação de calos foi 
COSTA, N.L., DAROS, E. e MORAES, A. Utilização de bioestimulantes na cultura da cana-deaçúcar (Saccharum officinarum L.). PUBVET, Londrina, V. 5, N. 22, Ed. 169, Art. 1137, 2011.

favorecida quando explantes foram incubados em meio MS suplementado com $1,0 \mathrm{mg} / \mathrm{L}$ de 2,4-D e 0,2 mg/L de citocinina (LIMA; CAETANO, 2002).

\section{Retardantes do Metabolismo}

São substâncias que atuam dentro da planta inibindo a produção natural de giberelinas, o que modifica a morfologia da planta, com redução do seu tamanho. Eles afetam a formação de células e a elongação do entrenó abaixo do meristema, de modo que são obtidas plantas pequenas com o desenvolvimento de flores normais. O comprimento do entrenó é reduzido, contudo o número de entrenós normalmente não é afetado. Além disso, as folhas são menores e ficam com um verde mais intenso (BARRETT, 1992).

Os inibidores da síntese de giberelinas são usados comercialmente para evitar o alongamento em algumas plantas. Em cultivo de flores, plantas pequenas e fortes como lírios, crisântemos e poinsétias são desejáveis e a restrição no crescimento por alongamento pode ser obtida por aplicações de inibidores da síntese de giberelinas. Também são muito usados em cereais, para evitar o acamamento e em arbustos nas margens das estradas (TAIZ; ZEIGER, 2009). Os produtos pertencentes ao grupo dos inibidores da biossíntese de giberelinas são: CCC (cloreto de 2-cloroetil-trimetilamônio), também denominado Cycocel ou Chlormequat, Paclobutrazol (PBZ), Daminozide, Uniconazole, Alar entre outros. Há relatos de extensão na área foliar em plantas medicinais induzida pela aplicação de CCC, devido ao seu efeito na formação de clorofila e sua influência no número de ramos principais que aumentam de forma inversamente proporcional à sua concentração. Este fato pode ser devido à supressão da dominância apical, assim como da ramificação lateral que é induzida por concentrações baixas de CCC (STEFANINI et al., 2002). O CCC apresenta efeitos particulares na incidência de pragas e doenças, tanto quando aplicado via foliar ou via solo. Além disso, ele também pode reduzir o teor de aminoácidos em folhas de plantas e também alterar outras características fisiológicas como senescência de folhas, 
COSTA, N.L., DAROS, E. e MORAES, A. Utilização de bioestimulantes na cultura da cana-deaçúcar (Saccharum officinarum L.). PUBVET, Londrina, V. 5, N. 22, Ed. 169, Art. 1137, 2011.

teor de umidade e afetar a susceptibilidade de plantas ao ataque de afídeos (pulgões) (VAN ENDEN; COCKSHULL, 1967).

\subsection{Inibidores da Divisão Celular}

São compostos que inibem a divisão e diferenciação celular nas regiões meristemáticas da planta devido a uma interferência no metabolismo da citocinina. Nesta classe estão a hidrazina maléica (Retard) e o mefluidide (Embark) que inibem o crescimento vegetativo e o desenvolvimento de flores.

\subsection{Retardadores com Efeito Herbicida}

Estes compostos possuem efeito herbicida em pós-emergência, afetando o crescimento e desenvolvimento das plantas, em doses sub-letais, pela interrupção da síntese de aminoácidos ou de lipídeos, apresentando efeitos expressivos sobre o florescimento.

\subsection{Produtores de Etileno}

O ethefon é um produto que é hidrolisado na planta em etileno, restringindo o alongamento dos caules, raízes e folhas. É absorvido via foliar com conseqüente supressão do crescimento das folhas e parcial supressão do florescimento.

\section{Biorregulação e os biorreguladores}

É o processo de manipular um evento fisiológico de uma planta de forma a exprimir ou inibir sua ação. Os compostos biorreguladores são aqueles que em sua formulação contêm moléculas protagônicas para a expressão ou inibição de um processo bioquímico. Geralmente são fitohormônios (idênticos 
COSTA, N.L., DAROS, E. e MORAES, A. Utilização de bioestimulantes na cultura da cana-deaçúcar (Saccharum officinarum L.). PUBVET, Londrina, V. 5, N. 22, Ed. 169, Art. 1137, 2011.

aos compostos naturais) ou compostos químicos com algum efeito hormonal (sintetizados em um laboratório).

\subsection{Ação e balanço hormonal}

O conhecimento atual sobre a formação e função de compostos hormonais nas plantas, tem permitido explicar diversos processos fisiológicos sobre a regulação de seu crescimento e reprodução. As auxinas e giberelinas influem na divisão e o alongamento celular, enquanto as citocininas afetam apenas a divisão; no entanto também há inibidores desses processos que limitam o crescimento vegetal (TAIZ, ZEIGER, 2009). Outras funções mais específicas são o atraso do envelhecimento por citocininas; a dominância apical e a estimulação de formar raízes pelas auxinas; a inibição floral pelas giberelinas; a maturação e a queda de órgãos pelo etileno, etc. A regulação da expressão de eventos fisiológicos nas plantas está em função da quantidade e tipo de hormônios presentes, ou seja, o balanço hormonal nas diferentes partes da planta. Os biorreguladores devem prover à planta de um suplemento adicional de hormônios ou outros compostos para auxiliar seu metabolismo geral e, contribuindo para suportar melhor certas condições adversas ao desenvolvimento do cultivo; regular ou manipular um evento ou processo fisiológico específico (crescimento de planta, desenvolvimento e maturação dos frutos, queda de folha, queda de fruto, etc.)

\subsection{Biorreguladores}

O crescimento e o desenvolvimento de plantas são regulados tanto por fatores endógenos como por fatores externos. Os fatores endógenos são ativos não somente em nível celular e molecular, afetando os processos metabólicos via transcrição e tradução, mas também têm a função de coordenação do organismo como um todo, realizada por meio dos hormônios vegetais (LARCHER, 2006). Existem conceitos básicos para hormônio, regulador, 
COSTA, N.L., DAROS, E. e MORAES, A. Utilização de bioestimulantes na cultura da cana-deaçúcar (Saccharum officinarum L.). PUBVET, Londrina, V. 5, N. 22, Ed. 169, Art. 1137, 2011.

retardador e estimulante vegetal. Hormônio vegetal é um composto orgânico, não nutriente, de ocorrência natural, produzido na planta, que inibe, promove ou modifica processos morfológicos e fisiológicos do vegetal. Os reguladores vegetais são substâncias sintetizadas exógenamente e, quando aplicadas nas plantas possuem ações similares aos compostos vegetais conhecidos. Os retardadores ou reguladores vegetais são compostos sintéticos, que retardam a alongação e a divisão celular no meristema subapical. Os estimulantes vegetais se referem à mistura de reguladores vegetais, ou de um ou mais reguladores com compostos de natureza bioquímica diferente (aminoácidos, vitaminas) (CASTRO, 2006). Os hormônios vegetais desempenham um papel importante, podendo uniformizar a germinação, controlar o desenvolvimento vegetativo, aumentar a fixação de flores e frutos e antecipar ou atrasar a maturação dos produtos de interesse comercial (CATO; CASTRO, 2006). Estas substâncias são sinalizadoras, responsáveis por efeitos marcantes no desenvolvimento, atuando em concentrações muito baixas.

Os biorreguladores, cujos efeitos são similares aos hormônios vegetais conhecidos (auxinas, citocininas, giberelinas), desempenham um importante papel podendo uniformizar a germinação, estimular o desenvolvimento radicular e o perfilhamento, melhorar o enchimento de grãos e antecipar ou atrasar a maturação. Os principais biorreguladores são o tiametoxam, aldicarb e cianamida hidrogenada. Estas substâncias são eficientes quando aplicadas em pequenas doses, favorecendo o bom desempenho dos processos vitais da planta, permitindo obter melhores e maiores colheitas, mesmo sob condições ambientais adversas. São formulações à base de um ou dois compostos hormonais, cuja ação fisiológica está bem definida e a recomendação de sua aplicação tem um objetivo muito específico: regular ou manipular um determinado processo (SALISBURY; ROSS, 1994). Para conseguir o efeito desejado com o uso de biorreguladores específicos, é importante conhecer o processo regulado pelo hormônio ou grupo de hormônios, a dose necessária para manipular o processo, bem como o órgão da planta onde ocorrerão as reações. Em geral, os biorreguladores são formulados com altas concentrações 
COSTA, N.L., DAROS, E. e MORAES, A. Utilização de bioestimulantes na cultura da cana-deaçúcar (Saccharum officinarum L.). PUBVET, Londrina, V. 5, N. 22, Ed. 169, Art. 1137, 2011.

dos ingredientes ativos $(0,1$ a $50 \%)$, podendo ser aplicados em solução ou em pó molhável.

Os biorreguladores vegetais podem promover, inibir ou modificar processos fisiológicos e morfológicos do vegetal. Eles agem em conjunto nos processos de germinação, crescimento, desenvolvimento e produtividade da planta, proporcionando o equilíbrio necessário para que todas as atividades referentes às etapas fenológicas ocorram de forma harmônica (DAVIES, 2004; RUIZ, 1998). Para Salisbury e Ross (1994) os efeitos dos reguladores vegetais dependem da espécie, da parte da planta, do estádio de desenvolvimento, da concentração, da interação com outros compostos e dos fatores ambientais. Segundo Castro et al. (2002) o mecanismo de ação dos reguladores vegetais está associado à interação molecular direta e específica, que desencadeia uma sucessão de eventos bioquímicos e fisiológicos que produzirão respostas mensuráveis. Para atuar, os hormônios se ligam a receptores protéicos específicos, formando um complexo hormônio-receptor, que libera um mensageiro secundário que migra até o núcleo e provoca expressão gênica. Consequentemente, a formação do RNA mensageiro, a partir do DNA, induz a síntese de enzimas, que atuam nas ligações polissacarídicas, desencadeando o desenvolvimento celular.

O modo de ação destes compostos é dependente do local de síntese ou tecido aplicado, do tempo de síntese ou da aplicação, do nível de ação do composto, bem como da interação e interrelação funcional de diferentes hormônios e reguladores vegetais (VIEIRA, 2001). Segundo Ruiz (1998), o estudo da aplicação de reguladores vegetais em muitas espécies cultivadas, busca o domínio e controle dos processos fisiológicos das plantas, e de certo modo, sua ação tem mostrado resultados surpreendentes tanto pelas reações divergentes de plantas semelhantes ao emprego de um mesmo produto, como pela modificação de certas técnicas consideradas tradicionalmente imutáveis. Vieira (2001) relata que com a descoberta dos efeitos dos reguladores sobre as plantas cultivadas e os benefícios promovidos por estas substâncias, bem como as combinações desses produtos têm sido pesquisados com o objetivo de 
COSTA, N.L., DAROS, E. e MORAES, A. Utilização de bioestimulantes na cultura da cana-deaçúcar (Saccharum officinarum L.). PUBVET, Londrina, V. 5, N. 22, Ed. 169, Art. 1137, 2011.

melhorar de maneira qualitativa e quantitativa a produtividade das culturas. Essas substâncias, naturais ou sintéticas podem ser aplicadas diretamente nas plantas (folhas, frutos, caules, ramos, sementes, etc.), provocando alterações nos processos vitais e estruturais, com a finalidade de incrementar a produção, melhorar a qualidade e facilitar a colheita. Através destas substâncias pode-se interferir em diversos processos fisiológicos e/ou morfológicos, tais como a germinação, crescimento vegetativo, florescimento, frutificação, senescência e abscisão. Esta interferência depende das condições ambientais, das características e potencialidades genéticas da planta (VIEIRA; CASTRO, 2004).

Modesto (1994) relata que reguladores vegetais têm sido usados em muitas culturas para o controle do crescimento, influenciando o florescimento e aumentando o rendimento da cultura. Em citros estes compostos têm sido usados para regular o desenvolvimento do fruto, inibir brotações do portaenxerto e estimular as do enxerto. Segundo Coelho et al. (1983), o emprego de substâncias reguladoras de crescimento pode acelerar a taxa de crescimento das plantas. Sugere ainda que o emprego de práticas culturais como irrigação, adubação e controle de plantas invasoras são fundamentais para a obtenção de mudas com qualidade, além de reduzir o período de sua formação. O crescimento de plantas em altura deve-se a capacidade do ácido giberélico $\left(\mathrm{GA}_{3}\right)$ em estimular a expansão do caule. Arteca (1995) sugere que o uso desses compostos na agricultura tem um importante potencial para regular alguns, senão todos, os processos fisiológicos das plantas. Atualmente, o uso comercial desses compostos já constitui realidade para muitas culturas, tais como a soja, uva, laranja, feijão, manga, etc. (VIEIRA; CASTRO, 2004). A aplicação de biorreguladores e bioestimulantes vegetais, visando aprimorar os padrões de produtividade, tem apresentado resultados significativos nessa área, principalmente em regiões onde as culturas já atingiram um nível elevado de tecnologia e manejo. Os mesmos autores sugerem a palavra biorreguladores como sinônimos de reguladores vegetais e citam o produto comercial Stimulate $\AA$, como um bioestimulante. Atualmente, dentre os grupos de reguladores vegetais incluindo os endógenos e os 
COSTA, N.L., DAROS, E. e MORAES, A. Utilização de bioestimulantes na cultura da cana-deaçúcar (Saccharum officinarum L.). PUBVET, Londrina, V. 5, N. 22, Ed. 169, Art. 1137, 2011.

sintéticos, temos as auxinas, as giberelinas, as citocininas, o ácido abscísico, o etileno, os brassinosteróides, os jasmonatos, os salicilatos, as poliaminas e os compostos fenólicos (TAIZ; ZEIGER, 2009).

\subsection{Bioativadores e bioestimulantes}

Bioativadores são substâncias orgânicas complexas modificadoras do crescimento capazes de atuar em fatores de transcrição da planta e na expressão gênica, em proteína de membrana alterando o transporte iônico e em enzimas metabólicas capazes de afetar o metabolismo secundário, de modo a modificar a nutrição mineral, produzir precursores de hormônios vegetais, levando a síntese hormonal e a resposta das plantas a nutrientes e hormônios. Dois potentes inseticidas têm demonstrado esse efeito, o aldicarb e o thiametoxan (CASTRO, 2006).

Com a modernização da agricultura, vários avanços nas técnicas de cultivo têm sido obtidos, visando atenuar os fatores limitantes da produção tais como o clima, pragas e doenças. A fisiologia vegetal é um dos campos da ciência agronômica que tem promovido grandes avanços nos últimos anos através do advento de modernas técnicas como a produção de plantas por cultura de tecidos, manipulação genética e biotecnologia. Dentre estas, a utilização de bioativadores que visam aumentar o potencial produtivo das plantas, é uma prática de uso crescente na agricultura moderna e amplamente difundida nos países altamente tecnificados como Estados Unidos, Espanha, Chile, México e Itália. Os bioativadores proporcionam um melhor equilíbrio fisiológico, favorecendo uma melhor aproximação ao potencial genético da cultura. Essas substâncias quando aplicadas às plantas, modificam ou alteram vários processos metabólicos e fisiológicos específicos. No Brasil, o uso de bioativadores começa a ser explorado e vários experimentos têm demonstrado aumento quantitativo e qualitativo na produtividade (SERCILOTO, 2002).

Bioestimulantes são misturas de biorreguladores ou mistura entre um ou mais biorreguladores com outros compostos de natureza química diferente 
COSTA, N.L., DAROS, E. e MORAES, A. Utilização de bioestimulantes na cultura da cana-deaçúcar (Saccharum officinarum L.). PUBVET, Londrina, V. 5, N. 22, Ed. 169, Art. 1137, 2011.

como: aminoácidos, enzimas, vitaminas, sais minerais, etc. (CASTRO, 2006). Esse produto químico pode, em função da sua composição, concentração e proporção das substâncias, incrementar o crescimento e desenvolvimento vegetal estimulando a divisão celular, diferenciação e alongamento das células, podendo também, aumentar a absorção e a utilização de água e dos nutrientes pelas plantas (CASTRO; VIEIRA, 2001a). A concentração hormonal dos bioestimulantes quase sempre é baixa, menos e $0,02 \%$ ou $200 \mathrm{ppm}$ de cada hormônio em um litro, sendo as doses recomendadas de 0,5 a 1,0 litro/ha. Apesar de alguns estudos utilizando os bioestimulantes em diferentes culturas, os resultados obtidos até agora têm sido controversos, sendo necessárias, portanto, novas pesquisas para melhor avaliação dos efeitos destes produtos na agricultura, uma vez que seu uso tem sido propagado em várias regiões do mundo (VASCONCELOS, 2006). Por sua composição de múltiplos hormônios em baixas concentrações, bem como pelas doses recomendadas, a aplicação de um bioestimulante dificilmente poderá regular ou manipular um processo fisiológico. Deste modo, a ação do bioestimulante será um complemento no auxílio da manutenção fisiológica, o que pode ser muito importante em condições ambientais (seca, geada) ou bióticas limitantes (pragas e doenças).

\subsubsection{Stimulate $®$}

O Stimulate ${ }^{\circledR}$ é um produto da Stoller do Brasil Ltda., classificado como estimulante vegetal ou bioestimulante. É uma substância líquida, não viscosa, de coloração castanha, solúvel em água e de fácil e rápida absorção por sementes, raízes, ramos, folhas e frutos (VIEIRA; CASTRO, 2004). Pode ser aplicado via sementes, via foliar ou no sulco de plantio em diversas culturas. É composto por três reguladores vegetais: $0,009 \%$ de cinetina (citocinina), 0,005\% de ácido giberélico (giberelina) e 0,005\% de ácido indolbutírico (auxina), além de $99,981 \%$ de ingredientes inertes. Esse composto possui a capacidade de estimular o desenvolvimento radicular, aumentando a absorção de água e nutrientes pelas raízes, podendo favorecer também o equilíbrio 
COSTA, N.L., DAROS, E. e MORAES, A. Utilização de bioestimulantes na cultura da cana-deaçúcar (Saccharum officinarum L.). PUBVET, Londrina, V. 5, N. 22, Ed. 169, Art. 1137, 2011.

hormonal da planta. O Stimulate $®$ também pode ser aplicado misturado a inseticidas, fungicidas, herbicidas, inoculantes e fertilizantes foliares, sem nenhum inconveniente (CASTRO et al., 1998). O bioestimulante atua de forma eficiente e eficaz sobre diversos processos fisiológicos fundamentais das plantas superiores, tais como germinação de sementes, vigor inicial de plântulas, crescimento e desenvolvimento radicular e foliar, além de produção de compostos orgânicos, aspectos que irão contribuir positivamente na obtenção de altos índices de produtividade com excelente qualidade nos produtos finais. Castro e Vieira (2001b) relatam que devido aos efeitos adicionais que existem entre os grupos de reguladores vegetais que promovem o crescimento e desenvolvimento dos vegetais, é crescente a utilização de produtos denominados bioestimulantes, definidos como a mistura de dois ou mais reguladores vegetais ou de reguladores vegetais com outras substâncias, tais como aminoácidos, nutrientes e vitaminas. De acordo com Echer et al. (2006), é crescente o número de estudos realizados para avaliar a interferência dos reguladores vegetais sobre diversas culturas. Sendo assim, cada vez mais pesquisas têm apontado para a utilização de produtos que apresentem em sua composição mais de um regulador vegetal, como é o caso dos bioestimulantes.

\subsubsection{Promalin $®$}

O Promalin $®$ é um composto comercial da Abbott Laboratories, contendo dois fitorreguladores naturais, sendo $1,8 \%$ das giberelinas $G_{4}$ e $G A_{7}$ e $1,8 \%$ da citocinina BA (Benziladenina), além de $96,4 \%$ de ingredientes inertes. A mistura é utilizada com o objetivo de promover o aumento na divisão e o alongamento celular (VALENT BIOSCIENCES, 2010). Diversos usos têm sido atribuídos ao Promalin $\AA$, tais como favorecer o crescimento de ramos laterais em pereira (KEEVER et al., 1993) e macieira (ROSSI et al., 2002) além de melhorar a qualidade da maçã, no que se refere à forma do fruto, tamanho e redução da incidência de "russeting". 


\subsubsection{Activa 47}

É uma mistura de fitohormônios naturais como auxinas, giberelinas e citocininas. A combinação estimula a divisão celular e o crescimento, induzindo a floração de gemas axilares, aumenta o crescimento dos caules, promove a floração e a maturação de frutos. Contém 12,4\% de N, 12\% de anidro fosfórico, 6,5\% de matéria orgânica, 6,0\% de aminoácidos e 9,6\% de mistura dos hormônios.

\subsubsection{Albamín}

É um ativador biológico natural do crescimento, sendo constituído por aminoácidos de baixo peso molecular. É um fertilizante de origem natural com um alto e balanceado conteúdo de aminoácidos livres. É aplicado através das folhas, sendo os aminoácidos rapidamente absorvidos. Promove maior rendimento, redução dos efeitos de queda prematura das gemas e melhora as propriedades organolépticas dos frutos.

\section{Uso de Biostimulantes na Cana-de-Açúcar}

Atualmente, com a utilização de técnicas avançadas para o cultivo de cana-de-açúcar, aumentos quantitativos e qualitativos na produção podem ser alcançados com a aplicação de reguladores vegetais. Essas substâncias podem ser aplicadas diretamente nas plantas, promovendo alterações nos processos vitais e estruturais e possibilitando incrementos no teor de sacarose, precocidade de maturação e aumento na produtividade das culturas (MARTINS; CASTRO, 1999; CAPUTO et al., 2008). Em razão dos inúmeros benefícios obtidos com a aplicação dessas substâncias sobre as plantas cultivadas, combinações desses produtos têm sido estudadas. Essas misturas são chamadas de estimulantes vegetais ou bioestimulantes e são eficientes quando aplicadas em pequenas doses, favorecendo o crescimento e o 
COSTA, N.L., DAROS, E. e MORAES, A. Utilização de bioestimulantes na cultura da cana-deaçúcar (Saccharum officinarum L.). PUBVET, Londrina, V. 5, N. 22, Ed. 169, Art. 1137, 2011.

desenvolvimento da planta, mesmo sob condições ambientais adversas (CASILLAS et al., 1986). Estes funcionam como ativadores do metabolismo das células, dão vigor ao sistema imunológico, reativam processos fisiológicos nas diferentes fases de desenvolvimento, estimulam o crescimento radicular, induzem a formação de novos brotos, melhoram a qualidade e quantidade do produto.

A partir da década de 70 do século passado, alguns trabalhos foram desenvolvidos no Brasil e em outros países para verificar o efeito do etefon na brotação e no desenvolvimento inicial da cana-de-açúcar, visando a maiores perfilhamento e produção final de colmos (LUCCHESI et al., 1979; MILLHOLLON; LEGENDRE, 1995; WIEDENFELD, 2003). Porém, a ação de um produto hormonal pode ser limitada por diversos fatores, dentre eles, a nutrição. Sendo assim, a nutrição adequada do canavial é imprescindível para se alcançarem maiores resultados (ORLANDO FILHO, 1993). Os macronutrientes desempenham função importante no desenvolvimento e na produtividade da cana-de-açúcar, enquanto que os micronutrientes atuam principalmente nos processos enzimáticos das plantas. A aplicação de nutrientes em solução ou suspensão na parte aérea da planta, visando a corrigir possíveis deficiências nutricionais não atendidas pela adubação de base, vem a ser a adubação foliar (VITTI; MAZZA, 2002).

As colheitas anuais e rebrotas fazem com que a cana-de-açúcar seja considerada semi-perene. A cada ciclo de colheita dos colmos tem início a brotação da soca, e um novo processo de perfilhamento é estabelecido (RODRIGUES, 1995; SILVA et al., 2008). Entretanto, mantém-se um canavial economicamente produtivo por cinco a seis cortes, quando a produtividade média atinge ao redor de $65 \mathrm{t} / \mathrm{ha}$. Maximizar o manejo varietal, tendo em vista a interação genótipos $\mathrm{x}$ longevidade da cultura, torna-se necessário para a busca da economicidade dessa atividade agrícola. Silva et al. (2010) avaliaram o efeito de bioestimulantes associados ou não a fertilizantes foliares (Stimulate ${ }^{\circ}$ a $0,5 \mathrm{~L} \mathrm{ha}{ }^{-1}$; Stimulate ${ }^{\circledR}$ a $0,5 \mathrm{~L} / \mathrm{ha}+$ Starter $\mathrm{N} \otimes$ a $3,0 \mathrm{~L} / \mathrm{ha}$; Stimulate $\AA$ a $0,5 \mathrm{~L} / \mathrm{ha}+$ Starter $\mathrm{N} \circledast$ a 3,0Lha + Cellerate $\AA$ a 0,5L/ha; Etefon 
COSTA, N.L., DAROS, E. e MORAES, A. Utilização de bioestimulantes na cultura da cana-deaçúcar (Saccharum officinarum L.). PUBVET, Londrina, V. 5, N. 22, Ed. 169, Art. 1137, 2011.

a 3,0L/ha), em cinco cultivares de cana (IAC87-3396, IAC91-2218, IAC914216, IAC91-5155 e IACSP93-6006). O Stimulate ${ }^{\circledR}$ (Sti) apresenta em sua composição $90 \mathrm{mg} / \mathrm{L}$ de cinetina, $50 \mathrm{mg} / \mathrm{L}$ de ácido giberélico e $50 \mathrm{mg} / \mathrm{L}$ de ácido 4-indol-3-ilbutírico. O Starter $\mathrm{N} \circledast(\mathrm{StaN})$ é um fertilizante foliar composto à base de nitrogênio, enxofre, boro, cobre, manganês e zinco. O fertilizante Cellerate ${ }^{\circledR}$ (Cel) é composto de $\mathrm{P}_{2} \mathrm{O}_{5}$, enxofre, molibdênio e zinco. No tratamento etefon, foi aplicado o produto comercial Zaz $(480 \mathrm{~g} / \mathrm{L})$. Os genótipos de cana-de-açúcar avaliados responderam diferentemente ao emprego de biorreguladores, associados ou não a fertilizantes foliares, em soqueira. 0 etefon proporcionou melhor perfilhamento, com resposta dependente do genótipo, porém esse incremento no número de perfilhos não refletiu em maior produtividade. A aplicação de Stimulate ${ }^{\circledR}$ e fertilizantes líquidos não proporcionou efeitos na qualidade tecnológica da cana-de-açúcar. Há aumento da produtividade de colmos e de açúcar em soqueira, independente do genótipo, com o emprego do biorregulador Stimulate $\Re$, com ou sem complementação de fertilizante líquido, o que indicou a possibilidade do aumento da longevidade dos canaviais (Tabela 1). Kimura e Beauclair (2009), avaliando diferentes bioestimulantes, sobre a brotação da cana, aplicados diretamente nos sulcos de plantio, não constataram efeitos significativos da aplicação de biostimulantes no perfilhamento da cana. Resultados semelhantes foram reportados por Sousa e Korndörfer (2010) que não detectaram efeitos significativos de bioestimulantes sobre a produtividade e rendimento industrial da cana cultivar RB92-5345 (Tabela 2). Da mesma forma, Mendes (2009) reportou aumentos significativos na germinação e emissão de perfilhos da cana com a aplicação de ethefon (900 mg/L), enquanto que o Stimulate e o thiometoxan retardaram a brotação até os 45 dias após o plantio. Silva et al. (2007) avaliaram os efeitos de reguladores de crescimento como potencializadores do perfilhamento e da produtividade em cana-soca. Os reguladores de crescimento aplicados antes da colheita da cana-de-açúcar não prejudicaram a brotação da cana-soca seguinte. Houve efeito do estimulante na emergência da brotação e perfilhamento, observado até seis meses após o 
COSTA, N.L., DAROS, E. e MORAES, A. Utilização de bioestimulantes na cultura da cana-deaçúcar (Saccharum officinarum L.). PUBVET, Londrina, V. 5, N. 22, Ed. 169, Art. 1137, 2011.

corte da cana-de-açúcar. O etefon promoveu maiores produtividades de colmos e de açúcar na cana-soca subseqüente. Houve diferenças entre genótipos quanto à resposta do comprimento de colmos em relação aos reguladores de crescimento sulfometuron-metil e etefon. Para o genótipo IAC91-5155, o uso de sulfometuron-metil e etefon reduziu o comprimento de colmos na cana-soca seguinte. Não houve efeito dos reguladores de crescimento sobre a qualidade tecnológica da cana-de-açúcar. Miguel et al. (2009), avaliando a economicidade da aplicação de bioestimulantes na canade-açúcar, constataram que o índice de lucratividade com a utilização de Stimulate ${ }^{\circledR}$ no tolete $(26,22 \%)$ e via foliar $(25,48 \%)$ foram bem superiores ao da testemunha $(13,09 \%)$; a dose de $0,5 \mathrm{l} / \mathrm{ha}$ de Stimulate $\AA$ aplicada nos toletes, conjugada aos tratamentos fitossanitários no plantio, resultou em maior produtividade e, consequentemente, maior índice de lucratividade. 
COSTA, N.L., DAROS, E. e MORAES, A. Utilização de bioestimulantes na cultura da cana-deaçúcar (Saccharum officinarum L.). PUBVET, Londrina, V. 5, N. 22, Ed. 169, Art. 1137, 2011.

Tabela 1. Efeito de bioestimulantes, associados ou não, a fertilizantes foliares, sobre a produtividade de cana por hectare, em tonelada de cana por hectare $(\mathrm{TCH})$, teor de sacarose na cana, em pol\% cana (PCC), fibra na cana (\%), açúcar teónico recuperável (ATR - kg/ton) e produtividade de açúcar, em tonelada de pol por hectare (TPH).

\begin{tabular}{lc|c|ccc|}
\hline \multicolumn{1}{c|}{ Tratamentos } & TCH & PCC & Fibra & ATR & TPH \\
\hline Stimulate & $90,49 \mathrm{ab}$ & $16,01 \mathrm{a}$ & $11,43 \mathrm{ab}$ & $156,97 \mathrm{a}$ & $14,56 \mathrm{a}$ \\
Stimulate + Starter & $86,28 \mathrm{~b}$ & $16,01 \mathrm{a}$ & $11,31 \mathrm{~b}$ & $157,06 \mathrm{a}$ & $13,88 \mathrm{ab}$ \\
Stimulate + Starter + Cellerate & $91,79 \mathrm{a}$ & $15,63 \mathrm{a}$ & $11,30 \mathrm{~b}$ & $153,64 \mathrm{a}$ & $14,42 \mathrm{a}$ \\
Etephon & $80,14 \mathrm{c}$ & $15,99 \mathrm{a}$ & $11,79 \mathrm{a}$ & $156,79 \mathrm{a}$ & $12,89 \mathrm{bc}$ \\
Testemunha & $74,50 \mathrm{~d}$ & $16,07 \mathrm{a}$ & $11,52 \mathrm{ab}$ & $157,49 \mathrm{a}$ & $12,00 \mathrm{c}$ \\
\hline
\end{tabular}

Fonte: Silva et al. (2010)

Tabela 2. Efeito de bioestimulantes, associados ou não, a fertilizantes foliares, sobre a produtividade de cana por hectare, em tonelada de cana por hectare $(\mathrm{TCH})$, teor de sacarose na cana, em pol\% cana (PCC), fibra na cana (\%), açúcar teónico recuperável (ATR - kg/ton) e produtividade de açúcar, em tonelada de pol por hectare (TPH) da cultivar RB925345 .

\begin{tabular}{l|c|c|ccc}
\hline \multicolumn{1}{c|}{ Tratamentos } & TCH & PCC & Fibra & ATR & TPH \\
\hline Testemunha & $133 \mathrm{a}$ & $17,42 \mathrm{a}$ & $12,63 \mathrm{a}$ & $170,21 \mathrm{a}$ & $20,79 \mathrm{a}$ \\
Ubyfol & $135 \mathrm{a}$ & $17,82 \mathrm{a}$ & $12,68 \mathrm{a}$ & $173,71 \mathrm{a}$ & $21,29 \mathrm{a}$ \\
Potamol Plus & $133 \mathrm{a}$ & $17,92 \mathrm{a}$ & $12,87 \mathrm{a}$ & $174,80 \mathrm{a}$ & $21,48 \mathrm{a}$ \\
Starter & $135 \mathrm{a}$ & $17,76 \mathrm{a}$ & $12,80 \mathrm{a}$ & $173,14 \mathrm{a}$ & $21,26 \mathrm{a}$ \\
Stimulate & $130 \mathrm{a}$ & $17,73 \mathrm{a}$ & $12,72 \mathrm{a}$ & $173,04 \mathrm{a}$ & $21,20 \mathrm{a}$ \\
Stimulate + Starter & $134 \mathrm{a}$ & $17,60 \mathrm{a}$ & $13,01 \mathrm{a}$ & $171,79 \mathrm{a}$ & $21,15 \mathrm{a}$ \\
\hline
\end{tabular}

Fonte: Sousa e Korndörfer (2010)

\section{Considerações Finais}

O uso de bioestimulantes na cultura da cana-de-açúcar é uma prática de manejo que potencialmente pode incrementar sua produtividade e o seu rendimento industrial, favorecendo o bom desempenho dos processos vitais da planta, permitindo obter melhores e maiores colheitas, mesmo sob condições ambientais adversas.

Para o efeito desejado com o uso de bioestimulantes específicos é importante conhecer o processo regulado pelo hormônio ou grupo de hormônios, a dose necessária para manipular o processo, bem como o órgão da planta onde ocorrerão as reações. Por sua composição de múltiplos hormônios em baixas concentrações, bem como pelas pequenas doses 
COSTA, N.L., DAROS, E. e MORAES, A. Utilização de bioestimulantes na cultura da cana-deaçúcar (Saccharum officinarum L.). PUBVET, Londrina, V. 5, N. 22, Ed. 169, Art. 1137, 2011.

recomendadas, a aplicação de um bioestimulante dificilmente poderá regular ou manipular um processo fisiológico. O bioestimulante pode representar um complemento no auxílio da manutenção fisiológica, o que pode ser muito importante em condições ambientais (seca, geada) ou bióticas limitantes (pragas e doenças).

\section{Referências Bibliográficas}

ANDRADE, A.; CELEDÓN, P.A.F.; LABATE, C.A. O proteoma da madeira. Biotecnologia Ciência e Desenvolvimento, n.36, p.10-17, 2006.

ARTECA, R.D. Plant growth substances: principles and applications. New York: Chapman \& Hall, 1995. 332p.

AYUB; R.A.; GEBIELUCA, A.N. Embriogênese somática em genótipos de café (Coffea arabica) é citocinina dependente. Ci. Agr. Eng., Ponta Grossa, v.9, n.2, p.25-30, 2003.

BARRETT, J.E. Mechanisms of action. In: TAYAMA, H.K.; LARSON, R.A; HAMMER, P.A et al. (Eds.). Tips on the use of chemical growth regulators on floriculture crops. Columbus: Ohio Florists' Association. 1992. p.12-18.

BEWLEY, J. D.; BLACK, M. Seeds: physiology of development and germination. 2.ed. New York: Plenum Press, 1994. p.445

CALDAS, $\ulcorner$ L.S. $;\ulcorner$ HARADASAN, $\ulcorner$ P. $;\ulcorner$ FERREIRA, $\ulcorner$ M.E. Meios nutritivos. In: TORRES, A.C.; ALDAS, L.S. (Eds.). Técnicas e aplicações de cultura de tecidos de plantas. Brasília: Embrapa Hortaliça, 1990. 433p. Г

CAMILI, E.C. Ação de bioreguladores na brotação, produção e algumas características físico-químicas de uva do cultivar superior Seedless. Botucatu: Universidade Estadual Paulista, 2007. 206p. Tese de Doutorado em Agronomia.

CAPUTO, M.M.; BEAUCLAIR, E.G.F.; SILVA, M.A. et al. Resposta de genótipos de cana-deaçúcar à aplicação de indutores de maturação. Bragantia, v.67, n.1, p.15-23, 2008.

CASILLAS, J. C.; LONDONO, J.; GUERREIRO, H. et al. Análisis cuantitativo de la aplicación de cuatro bioestimulantes en el cultivo rábano (Raphanus sativus L.). Acta Agronómica, Palmira, v.36, p.185-195, 1986.

CATO, $\ulcorner$ S.C. Ação de bioestimulante nas culturas do amendoizeiro, sorgo e trigo e interações hormonais entre auxinas, citocininas e giberelinas. Piracicaba: ESALQ, 2006. 74f. Dissertação de Mestrado em Fitotecnia.

CATO, S.C.; CASTRO, P.R.C. Redução da estatura de plantas de soja causada pelo ácido 2,3,5 - triiodobenzóico. Ciência Rural, v.36, n.3, 2006.

CASTRO, P.R.C. Agroquímicos de controle hormonal na agricultura tropical. Piracicaba: ESALQ. 2006. 46p.

CASTRO, P.R.C.; SENA, J.O.A.; KLUGE, R.A. Introdução a fisiologia do desenvolvimento vegetal. Maringá: Universidade Estadual de Maringá, 2002. 255p.

CASTRO, P.R.C.; VIEIRA, E.L. Aplicações de reguladores vegetais na agricultura tropical. Guaíba: Agropecuária, 2001a. 132p 
CASTRO, P.R.C.; VIEIRA, E.L. Ação de bioestimulante na germinação de sementes, vigor das plântulas, crescimento radicular e produtividade de soja. Revista Brasileira de Sementes, v.23, n.2, p.222-228, 2001b.

CASTRO, P.R.C; PACHECO, A.C; MEDINA, C.L. Efeitos de stimulate e de micro-citros no desenvolvimento vegetativo e na produtividade da laranjeira "pêra" (Citrus sinensis L. Obeck). Scientia Agrícola, v.55, n.2, p. 338-341, 1998.

COELHO, Y.S.; OLIVEIRA, A.A.R.; CALDAS, R.C. Efeitos do ácido giberélico $\left(\mathrm{GA}_{3}\right)$ no crescimento do porta-enxerto para citros. Pesquisa Agropecuária Brasileira, v.18, n.11, p.1229-1232, 1983.

COLL, J.B.; RODRIGO, G.N.; GARCIA, B.S. et al. Fisiologia vegetal. Madrid: Ediciones Pirâmide, 2001. 662p.

DAVIES, P.J. Plant hormones: biosynthesis, signal transduction, action. Dordrecht: Kluwer Academic Publishers, 2004. 750p

DAVIES, P.J. Plant hormones and their role in plant growth and development. New York: Martinus Nijhoff Publishers, 1987. 732p.

ECHER, M.M.; GUIMARÃES, V.F.; KRIESER, C.R. et al. Uso de bioestimulante na formação de mudas de maracujazeiro amarelo. Sergina Ciências Agrárias, v.27, n.3, p.351-359, 2006.

GASPAR, T.; KEVERS, C.; PENEL, C. et al. Plant hormones and plant growth regulator in plant tissue culture. In Vitro Cellular Development Biology-Plant, v.32, p.272-289, 1996.

HARTMANN, H.T.; KOFRANEK, A.M.; RUBATZKY, V.E. et al. Plant science: growth, development and utilization of cultivated plants. New Jersey: Regents Prentice Hall, 2.ed. $1988,674 p$.

KEEVER, G.J.; FOSTER, W.J.D.; WEST, M.S. Increasing "Bradford" pear crotch angles and lateral shoot counts with Benzyladenine and Promalin sprays. HortScience, v.28, n.6, p.678, 1993.

KIMURA, W.J.; BEAUCLAIR, E.G.F. Resposta da brotação a diferentes bioestimulantes na cultura da cana-de-açúcar. Piracicaba; ESALQ, 2009. 2p.

LARCHER, W. Ecofisiologia vegetal. São Carlos: Rima, 2006. p.295-338.

LIMA, A.S.; CAETANO, L.C. Produção de naftoquinonas em culturas de calos de Tabebuia caraíba (MART), Bignoniaceae. In: CONGRESSO NACIONAL DE BOTÂNICA, 53., 2002, Recife. Resumos... Recife: SBB, p.25, 2002.

LUCCHESI, A.A.; FLORENCIO, A.C.; GODOY, O.P. et al. Influência do ácido 2-cloroetil fosfônico na indução de perfilhamento em cana-de-açúcar (Saccharum spp.) - Variedade NA 56-79. Brasil Açucareiro, Rio de Janeiro, v.93, n.4, p.19-27, 1979.

MARTINS, M.B.G.; CASTRO, P.R.C. Efeito da giberelina e ethefon na anatomia de plantas da cana-de-açúcar. Pesquisa Agropecuária Brasileira, v.34, p.1855-1863, 1999.

MENDES, L.S.; CASTRO, P.R.; ROSSI, G. Desenvolvimento inicial de mini-toletes de cana-deaçúcar submetidos a tratamentos com agroquímicos. In: CONGRESSO BRASILEIRO DE FISIOLOGIA VEGETAL, 12., 2009, Fortaleza. Anais... Fortaleza: UFC, 2009. 2p.

METIVIER, J.R. Giberelinas. In: FERRI, M.G. Fisiologia vegetal. São Paulo: EDUSP, 1979. v.2, cap.5, p.129-161.

MIGUEL, F,B.; SILVA, J.A.A.; BÁRBARO, I.M. et al. Viabilidade econômica na utilização de um regulador vegetal em cana-planta. Informações Econômicas, v.39, n.1, p.53-59, 2009

MILLHOLLON, R.W.; LEGENDRE, B.L. Influence of ethephon on plant population and yield of sugarcane (Saccharum spp. hybrids). Plant Growth Regulation Society of America Quarterly, v.23, n.1, p.17-30, 1995. 
MODESTO, J.C. Efeitos de diferentes reguladores de crescimento sobre o desenvolvimento de porta-enxertos de citros. Botucatu: Universidade Estadual Paulista, 1994. 127f. Dissertação de Mestrado em Agronomia.

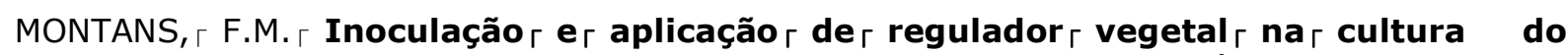
amendoim cultivado em dois solos de diferentes texturas. Marília: Universidade de Marília, 2007, 55p. Dissertação de Mestrado em Fitotecnia.

ORLANDO FILHO, J. Calagem e adubação da cana de açúcar. In: CÂMARA, G.M.S.; OLIVEIRA, E.A.M. (Eds). Produção de cana-de-açúcar. Piracicaba: FEALQ/USP, 1993. p.133-146.

RAMACHANDRA RAO, S.; RAVISHANKAR, G.A. Plant cell cultures: chemical factories of secondary metabolites. Biotechnology Advances, v.20, p.101-153, 2002.

RAVEN, P.H.; EVERT, R.F.; EICHHORN, S.E. Biologia Vegetal. Rio de Janeiro: Guanabara Koogan, 2001, 906p.

RODRIGUES, J.D. Fisiologia da cana-de-açúcar. Botucatu: Instituto de Biociências, Universidade Estadual Paulista, 1995. 99p.

RODRIGUES, T.J.D.; LEITE, I.C. Fisiologia vegetal hormônios das plantas. Jaboticabal: Funep, 2004. 78p.

ROSSI, A.; RUFATO, L.; GIACOBBO, C.L. et al. The use of Promalin on one-year old apple trees (cv. Catarina). In: INTERNATIONAL HORTICULTURAL CONGRESS, 26., 2002, Toronto. Abstracts... Toronto: Acta Horticultural, 2002. p.347.

RUIZ, V.S. Fitorreguladores. In: El parásito de la vid: estrategias de protección razonada. 4.ed. Madrid: Mundi-Prensa, 1998. p.303-306.

SALISBURY, F.B.; ROSS, C.W. Fisiologia vegetal. México: Iberoamérica, 1994. 759p.

SERCILOTO, C.M. Mais produção: os bioativadores são capazes de aumentar a qualidade dos frutos. Cultivar HF, Pelotas, v.2, n.13, p20-21, 2002

SILVA, M.A.; JERONIMO, E.M.; LÚCIO, A.D. Perfilhamento e produtividade de cana-de-açúcar com diferentes alturas de corte e épocas de colheita. Pesquisa Agropecuária Brasileira, v.43, n.8, p.979-986, 2008.

SILVA, M.A.; CATO, S.C.; COSTA, A.G.F. Produtividade e qualidade tecnológica da soqueira de cana-de-açúcar submetida à aplicação de biorregulador e fertilizantes líquidos. Ciência Rural, v.24, n.2, p.23-33, 2010.

SILVA, M.A.; GAVA, G.J.; CAPUTO, M.M. et al. Uso de reguladores de crescimento como potencializadores do perfilhamento e da produtividade em cana-soca. Bragantia, v.66, n.4, p.545-552, 2007.

SOUSA, R.T.X.; KORNDÖRFER, G.H. Uso de micronutrientes e estimulantes de crescimento na produtividade e parâmetros tecnológicos da cana-de-açúcar. In: FERTBIO 2010, Guarapari, 2010. Anais... Guarapari: SBCS, 2010, 4p.

SOROKIN, $\ulcorner$ H.P.; $\ulcorner$ MATHUS, $\ulcorner$ S.N.; $\ulcorner$ THIMANN, $\ulcorner$ K.V. The effects of auxins and kinetin on xylem differentiation in the pea epicotyls. $\ulcorner$ American Journal of Botany, v.49, p.444-454, 1962.

STEFANINI, M.B.; RODRIGUES, S.D.; MING, L.C. Ação de fitorreguladores no crescimento da erva-cidreira-brasileira. Horticultura Brasileira, v.20, n. 1, p.18-23, 2002.

TAKAHASHI, E.K. Transferência do gene atacina A para plantas de maracujá amarelo (Passiflora edulis Sims f. flavicarpa Deg.) por biobalística. Piracicaba: ESALQ, 2002, 123p. Tese de Doutorado em Engenharia Agrícola.

TAIZ, L. ; ZEIGER, E. Fisiologia vegetal. Porto Alegre: Artmed, 2009. 819p.

VALENT BIOSCIENCES. Disponível em: <http:www.valentbiosciences.com>. Acesso em: 3 out. 2010. 
VALOIS, A.C.C. Cultura de tecidos vegetais. In: CID, L.P.B. Introdução aos hormônios vegetais. Brasília: Embrapa Recursos Genéticos e Biotecnologia, 2000. p.7-18.

VAN ENDEN, H.F.; COCKSHULL, K.E. The effects of soil aplications of (2-cloroethyl)trimethylammonium chloride on leaf area and dry matter production by the brussels sprout plant. Journal of Experimental Botany, v.18, n. 57, p. 707-715, 1967.

VASCONCELOS, A.C.F. Uso de bioestimulantes nas culturas de milho e soja. Piracicaba: ESALQ, 2006. 111p. Tese de Doutorado em Engenharia Agrícola.

VIEIRA, E.L. Ação de bioestimulante na germinação de sementes, vigor de plântulas, crescimento radicular e produtividade de soja (Glycine max (L.) Merrill), feijoeiro (Phaseolus vulgaris L.) e arroz (Oryza sativa L.). Piracicaba: ESALQ, 2001. 122p. Tese de Doutorado em Agronomia.

VIEIRA, E.L.; CASTRO, P.R.C. Ação de bioestimulante na cultura da soja (Glycine max (L.) Merrill). Cosmópolis: Stoller do Brasil, 2004. 74p.

VIEIRA, E.L.; MONTEIRO, C.A. Hormônios vegetais. In: CASTRO, P.R.C.; SENA, J.O.A.; KLUGE, R.A.M. Introdução à fisiologia do desenvolvimento vegetal. Maringá: Eduem, 2002. p.79-104.

VITTI, G.C.; MAZZA, J.A. Planejamento, estratégias de manejo e nutrição da cultura de cana-de-açúcar. Piracicaba: POTAFOS, 2002. 16p. (Informações Agronômicas, 97).

WENT, F.W.; THIMANN, K.V. Biochemistry and mode of action of hormones. In: HOPKINS, W.G. Introduction to plant physiology. New York: Wiley, 1999. p.335-363.

WIEDENFELD, B. Enhanced sugarcane establishment using plant growth regulators. Journal of American Society of Sugarcane Technologists, Canal Point, v.23, p.48-61, 2003. 